\title{
UMA FERRAMENTA BASEADA EM OTIMIZAÇÃO PARA APOIAR DECISÕES DE PREPARAÇÃO E RESPOSTA EM LOGÍSTICA HUMANITÁRIA ${ }^{1}$
}

\author{
Francielly Marinho $^{a}$, Pedro Munaria*, Alfredo Moreno ${ }^{a}$, Douglas Alem ${ }^{b}$ \\ ${ }^{a}$ Departamento de Engenharia de Produção \\ Universidade Federal de São Carlos - UFSCAR, São Carlos-SP, Brasil \\ ${ }^{\mathrm{b} B u s i n e s s ~ S c h o o l ~}$ \\ University of Edinburgh, Escócia, Reino Unido
}

Recebido 30/11/2017, aceito 23/07/2018

\begin{abstract}
RESUMO
É notório o crescimento no número de desastres de causa natural ou antrópica no Brasil e no mundo. Entretanto, ainda é escassa a quantidade de abordagens científicas e ferramentas computacionais que culminam em uma aplicação acessível aos tomadores de decisão nas comunidades atingidas por essas catástrofes. Este trabalho aborda a otimização da tomada de decisão em operações humanitárias brasileiras. Neste contexto, propõe-se um modelo de localização de centros de auxílio e distribuição de suprimentos, para uso nas fases de preparação e resposta de desastres reais. Esse modelo foi implementado usando o Microsoft Excel, resultando em uma ferramenta de apoio à tomada de decisão que pode auxiliar em desastres brasileiros. Testes computacionais com a ferramenta foram realizados usando dados de um desastre ocorrido na Região Serrana do Rio de Janeiro. Os resultados indicam o potencial positivo de uma ferramenta baseada em otimização no suporte a decisões da logística humanitária.
\end{abstract}

Palavras-chave: Logística humanitária, Desastres, Otimização, Sistema de apoio à decisão.

\begin{abstract}
It is evident the increasing number of natural and man-made disasters in Brazil and worldwide. However, the proportion of scientific approaches and computational tools resulting in an accessible application for the decision makers acting in the communities that suffer with such catastrophes do not grow at the same rate. This study addresses the optimization of the decisionmaking process for the Brazilian humanitarian operations. In this context, we propose a deterministic location-distribution model to be used in preparedness and response of real disasters. We implemented the model in Microsoft Excel, resulting in a decision support tool that can be helpful in Brazilian disasters. We tested the tool using data from a disaster that occurred in the Mountain Region of Rio de Janeiro, Brazil. The results indicate the potential of an optimization-based tool to support the decision-making process in humanitarian logistics.
\end{abstract}

Keywords: Humanitarian logistics, Disasters, Optimization, Decision support system.

*Autor para correspondência. E-mail: munari@ dep.ufscar.br

DOI: 10.4322/PODes.2018.006 


\section{Introdução}

Segundo o Escritório para Redução de Riscos de Desastres das Nações Unidas (UNISDR, 2007), desastre é definido como uma séria ruptura no modo de funcionamento de uma comunidade ou sociedade envolvendo generalizada perda humana, material, econômica ou ambiental, que supera a capacidade da comunidade de se recuperar utilizando os próprios recursos. Os desastres têm crescido nas últimas décadas, não somente devido a fatores como o aumento populacional e ocupação humana desordenada, decorrentes de acelerados processos de industrialização e urbanização (Kobiyama et al., 2006), como também devido à vulnerabilização socioeconômica, que resulta no aumento da desigualdade social e pobreza (De Loyola Hummell et al., 2016; Alem et al., 2017).

O número de registros de desastres naturais ou humanos ocorridos nos últimos 35 anos quase quadruplicou. Apenas no ano de 2017, foram registrados no mundo um total de 529 desastres, 361 deles catástrofes naturais e 168 originados pela ação antrópica (EM-DAT, 2018). O Brasil é o único país do continente americano que aparece na lista dos dez países com o maior número de pessoas afetadas por desastres (51 milhões) no período de 1995 a 2015 (UNISDR, 2015).

A susceptibilidade de um país à ocorrência de desastres não se deve apenas à vulnerabilidade natural do mesmo (características geomorfológicas) mas também ao seu sistema de organização econômico, social, político e cultural. Desse modo, países em desenvolvimento, como o Brasil, são mais impactados por desastres, dado seus contextos de desenvolvimento histórico marcados pela desigualdade, fazendo com que a maioria da população ainda seja desfavorecida e mais vulnerável às catástrofes (Alcántara-Ayala, 2002). De fato, quando um risco natural, como enchentes e deslizamentos, atinge áreas em que grupos mais vulneráveis vivem, estes experienciam uma maior dificuldade em lidar com os seus pós efeitos, devido à falta de seguro, economias e créditos, ajuda humanitária, governo ineficiente e morosidade burocrática (Chang e Falit-Baiamonte, 2002). Como consequência, as populações que não são atendidas de forma adequada no processo de recuperação, ficam mais vulneráveis ao próximo risco natural.

Com a finalidade de minimizar as perdas humanas, materiais e ambientais de desastres, pode-se recorrer a estratégias de gestão operacional, como as oferecidas pela logística humanitária (LH). Esta é uma área da logística que se propõe a gerir de forma eficiente e eficaz o fluxo de suprimentos, serviços e pessoas, com o propósito de salvar vidas e aliviar o sofrimento de pessoas vulneráveis (Nogueira et al., 2007). Sua missão é minimizar o dano à vida daqueles expostos pela situação de desastre.

As atividades de gestão humanitária de desastres são constituídas por diversos atores que frequentemente possuem autonomia, interesse e níveis de competência diversos. As ações envolvem a atuação de órgãos governamentais, agências de auxílio humanitário, forças militares e organizações não governamentais (ONGs) (Balcik et al., 2010). No Brasil, a maior parte das ações de logística humanitária é coordenada pelo Sistema Nacional de Proteção e Defesa Civil (SINPDEC) que, por sua vez, é subordinado ao Ministério da Integração Nacional (MI).

A LH é dedicada à gestão de operações de todo o ciclo de vida dos desastres, que inclui as fases de mitigação, preparação, resposta e recuperação. Na fase de resposta, em comparação com as outras fases, há uma maior mobilização de recursos, maior urgência na tomada de decisões e maior impacto humano de eventuais falhas no processo decisório. Ademais, as operações de resposta ocorrem sob acentuada pressão dos atores envolvidos no processo e atenção dos meios de comunicação e sociedade em geral (Tomasini e Van Wassenhove, 2009).

Dessa forma, faz-se importante dedicar recursos materiais, tecnológicos e intelectuais para as operações de resposta de áreas atingidas por desastres. Enquanto as ciências humanas apresentam uma grande abundância de artigos na gestão de desastres, a modelagem matemática das operações humanitárias, embora tenha apresentado um crescimento considerável ao longo da última década, ainda é carente de aplicações práticas e propostas de ferramentas com potencial de utilização em situações reais. E uma vez que na gestão de desastres há diversidade de impactos e problemas, particularidades de incidentes, demanda dinâmica/estocástica e busca 
por soluções eficientes e efetivas, esse tema é bastante propício à Pesquisa Operacional (PO) (Altay e Green III, 2006).

Assim, este estudo aborda o uso da PO para a otimização de decisões que se encontram no escopo da logística humanitária no contexto nacional. Em especial, dá-se enfoque às decisões de preparação e resposta, pois é sabido que as operações de resposta são criticamente influenciadas pelas decisões tomadas na fase de preparação. Por essa razão, há uma tendência da literatura acadêmica em tratar de forma integrada tais decisões (Moreno et al., 2016). Dessa forma, espera-se com esse estudo propor uma ferramenta para auxiliar os profissionais humanitários brasileiros em seu processo decisório.

As contribuições deste trabalho são as seguintes: (a) fazer um levantamento da aplicação da PO em logística humanitária no contexto brasileiro; (b) propor um modelo matemático que auxilie nas decisões logísticas das fases de preparação e resposta humanitária em eventos de desastres; (c) criar uma ferramenta simples de apoio à tomada de decisão usando o modelo proposto, que possa, de fato, ser utilizada na prática para auxiliar o planejamento em eventos de desastres. Para verificar o potencial prático da ferramenta, são realizados testes com dados do Megadesastre ocorrido na Região Serrana do Rio de Janeiro em 2011.

O restante deste artigo está estruturado da seguinte forma. A Seção 2 é uma revisão da literatura de PO aplicada à logística humanitária, no contexto nacional. A Seção 3 apresenta uma caraterização do problema e a modelagem proposta. A implementação computacional da ferramenta de apoio à tomada de decisão é descrita na Seção 4. Na Seção 5, apresenta-se uma análise e discussão dos resultados obtidos com o uso da ferramenta aplicada ao caso real abordado. Por fim, a Seção 6 traz a conclusão do estudo.

\section{Revisão Bibliográfica}

Para analisar a aplicação da PO no suporte às decisões da logística humanitária no contexto nacional, foi realizada uma busca pelo tema em artigos de autores brasileiros publicados em periódicos nacionais e internacionais, além de teses e dissertações. Utilizou-se a Biblioteca Eletrônica SciELO para buscar artigos em periódicos nacionais; o ISIS Web of Science para procurar artigos em periódicos internacionais; o Banco de Teses e Dissertações CAPES (BTDC) e a Biblioteca Digital Brasileira de Teses e Dissertações (BDTD) para teses e dissertações. A busca foi limitada a trabalhos publicados entre 2010 e 2018 contendo os seguintes termos (e suas traduções em inglês) em títulos, tópicos ou palavras-chave: "logística humanitária" ou "operações humanitárias" e "pesquisa operacional" ou "modelo matemático" ou "modelo" ou "programação estocástica" ou "programação linear determinística". Estudos cuja proposta não se enquadrava no domínio da PO e que não abordavam questões humanitárias foram excluídos da análise. Como resultado, foram encontrados 20 trabalhos.

$\mathrm{Na}$ Tabela 1, são apresentados o ano e a base de dados dos trabalhos. Nota-se que a quantidade de trabalhos sobre PO e LH no contexto nacional é crescente e que a maioria corresponde a teses ou dissertações. Isso indica uma certa vanguarda dos estudos acerca deste tema.

Tabela 1: Ano de publicação e bases de dados dos trabalhos sobre PO e LH no contexto brasileiro.

\begin{tabular}{|c|c|c|c|c|c|c|c|c|c|c|}
\hline & $\mathbf{2 0 1 0}$ & $\mathbf{2 0 1 1}$ & $\mathbf{2 0 1 2}$ & $\mathbf{2 0 1 3}$ & $\mathbf{2 0 1 4}$ & $\mathbf{2 0 1 5}$ & $\mathbf{2 0 1 6}$ & $\mathbf{2 0 1 7}$ & $\mathbf{2 0 1 8}$ & Total \\
\hline BTDC e BDTD & 1 & 0 & 0 & 0 & 4 & 2 & 3 & 2 & 0 & 12 \\
\hline Scielo & 0 & 0 & 0 & 0 & 1 & 1 & 0 & 1 & 0 & 3 \\
\hline ISIS Web of Science & 0 & 0 & 0 & 0 & 0 & 1 & 2 & 0 & 2 & 5 \\
\hline Total & 1 & 0 & 0 & 0 & 5 & 4 & 5 & 3 & 2 & 20 \\
\hline
\end{tabular}

Fonte: Elaborado pelos autores.

Na Tabela 2, os trabalhos são classificados quanto ao tipo de abordagem de pesquisa, como sendo Analítico (AN), Empírico (EM) ou Aplicado (AP). Adicionalmente, a tabela mostra 
as principais decisões de LH que buscam ser apoiadas pela PO nos trabalhos considerados. Vale ressaltar que não foi encontrado nenhum artigo de revisão da literatura sobre trabalhos abordando a aplicação da PO em LH no contexto nacional.

Tabela 2: Tipo de abordagem usada e principais decisões apoiadas nos trabalhos sobre PO e LH no contexto brasileiro.

\begin{tabular}{|c|c|c|c|c|}
\hline & \multicolumn{3}{|c|}{ Abordagem } & \multirow[b]{2}{*}{ Principais decisões } \\
\hline & $\mathbf{A N}$ & EM & $\mathbf{A P}$ & \\
\hline \multicolumn{5}{|l|}{ ISIS Web of Science } \\
\hline Moreno et al. (2016) & & $\mathrm{x}$ & & $\begin{array}{l}\text { Localização de centros de auxílio, distribuição } \\
\text { de suprimentos, dimensionamento da frota, } \\
\text { alocação de demanda. }\end{array}$ \\
\hline Alem et al. (2016) & & $\mathrm{x}$ & & $\begin{array}{l}\text { Aquisição e distribuição de suprimentos, pré- } \\
\text { posicionamento de estoque, dimensionamento de } \\
\text { frota. }\end{array}$ \\
\hline Duhamel et al. (2016) & & $\mathrm{x}$ & & $\begin{array}{l}\text { Localização de facilidades, alocação de } \\
\text { demanda. }\end{array}$ \\
\hline Moreno et al. (2018) & & $\mathrm{x}$ & & $\begin{array}{l}\text { Localização de centros de auxílio, distribuição } \\
\text { de suprimentos, dimensionamento da frota, } \\
\text { alocação de demanda. }\end{array}$ \\
\hline Condeixa et al. (2017) & & $\mathrm{x}$ & & $\begin{array}{l}\text { Pré-posicionamento de estoques, localização de } \\
\text { centros de distribuição, distribuição de } \\
\text { suprimentos. }\end{array}$ \\
\hline \multicolumn{5}{|l|}{ Scielo } \\
\hline Bataglin e Alem (2014) & & $\mathrm{x}$ & & $\begin{array}{l}\text { Localização de centros de auxílio, distribuição } \\
\text { de suprimentos, dimensionamento da frota. }\end{array}$ \\
\hline Lima et al. (2015) & & $\mathrm{x}$ & & $\begin{array}{l}\text { Aquisição de suprimentos, seleção de } \\
\text { fornecedores. }\end{array}$ \\
\hline Moreno et al. (2017b) & & $\mathrm{x}$ & & $\begin{array}{l}\text { Localização de centros de auxílio, distribuição } \\
\text { de suprimentos, dimensionamento da frota, } \\
\text { alocação de demanda. }\end{array}$ \\
\hline \multicolumn{5}{|l|}{ BTDC e BDTD } \\
\hline Nogueira (2010) & & $\mathrm{x}$ & & $\begin{array}{l}\text { Localização de central de inteligência e suporte, } \\
\text { distribuição de suprimentos. }\end{array}$ \\
\hline Lima (2014) & & $\mathrm{x}$ & & $\begin{array}{l}\text { Aquisição de suprimentos, seleção de } \\
\text { fornecedores. }\end{array}$ \\
\hline Oliveira (2014) & & & $\mathrm{x}$ & $\begin{array}{l}\text { Planejamento do serviço de atendimento do } \\
\text { Corpo de Bombeiros. }\end{array}$ \\
\hline Bertazzo (2014) & $\mathrm{x}$ & & & $\begin{array}{l}\text { Fornecimento, pré-posicionamento de estoque, } \\
\text { distribuição de suprimentos. }\end{array}$ \\
\hline Feltrin (2014) & & $\mathrm{x}$ & & $\begin{array}{l}\text { Localização de depósitos e centrais de } \\
\text { assistência. }\end{array}$ \\
\hline Brito Jr. (2015) & & & $\mathrm{x}$ & $\begin{array}{l}\text { Localização de depósitos, pré-posicionamento } \\
\text { de materiais. }\end{array}$ \\
\hline Cavalcanti (2015) & $\mathrm{x}$ & & & Distribuição de suprimentos. \\
\hline Moreno (2015) & & $\mathrm{x}$ & & $\begin{array}{l}\text { Localização de centros de auxílio, distribuição } \\
\text { de suprimentos, dimensionamento da frota, } \\
\text { alocação de demanda. }\end{array}$ \\
\hline Rebouças (2016) & & $\mathrm{x}$ & & Roteamento de helicópteros. \\
\hline Xavier (2016) & & $\mathrm{x}$ & & Distribuição de suprimentos. \\
\hline Buzogany (2017) & & $\mathrm{x}$ & & Distribuição de suprimentos. \\
\hline Maculan (2017) & & $\mathrm{x}$ & & Fluxo de pessoas, alocação de recursos. \\
\hline
\end{tabular}

Fonte: Elaborado pelos autores. 
Apenas dois trabalhos foram encontrados com abordagem analítica. Nesta categoria, Bertazzo (2014) propõe um modelo conceitual para analisar os mecanismos de coordenação e as formas de colaboração na cadeia de suprimentos humanitária com foco em decisões de fornecimento, distribuição e pré-posicionamento de estoque. Cavalcanti (2015) analisa os principais critérios de desempenho ou objetivos adotados em modelos de PO para a tomada de decisão na distribuição de suprimentos em situações de desastre. $\mathrm{O}$ autor também discute a incompatibilidade entre os objetivos considerados na literatura e os objetivos reais considerados pelos tomadores de decisões.

A maioria dos trabalhos encontrados na revisão utiliza a abordagem empírica, ou seja, são inspirados e/ou consideram dados baseados em desastres reais para o desenvolvimento de modelos e/ou técnicas de PO que possam auxiliar na tomada de decisões, porém sem que exista uma aplicação prática de fato destas técnicas. Neste contexto, Nogueira (2010) apresenta um modelo multicritério de tomada de decisão (Analytic Hierarchy Process-AHP) para auxiliar na localização de uma central de inteligência e na distribuição de recursos emergenciais. $\mathrm{O}$ autor considera objetivos relacionados com a maximização da eficiência e a minimização do tempo de resposta, usando dados de deslizamentos de terra em Santa Catarina em 2008 para testar o modelo. Feltrin (2014), por outro lado, usa sistemas de informações geográficas junto com um modelo de simulação com o intuito de diminuir o tempo de resposta e o risco em inundações. São consideradas decisões de localização de armazéns e de centrais de assistência. O modelo é testado com dados da bacia do rio Jahu no estado de São Paulo.

Bataglin e Alem (2014) propõem um modelo de programação estocástica para apoiar as decisões de localização de centros de auxílio, distribuição de suprimentos e dimensionamento da frota minimizando os custos logísticos totais e a demanda insatisfeita. Os autores utilizaram dados baseados no desastre na Região Serrana do Rio de Janeiro de 2011 para validar o modelo. Lima (2014); Lima et al. (2015) realizam uma modelagem do processo de aprovisionamento de suprimentos utilizando Business Process Model Notation (BPMN) e propõem um modelo matemático para definir o melhor conjunto de fornecedores de suprimentos para desastres. Moreno (2015); Moreno et al. (2016, 2017a) acrescentam características adicionais ao problema proposto por Bataglin e Alem (2014), tais como reutilização de veículos e decisões adicionais de alocação de demanda a centros de auxílio. Os autores desenvolvem métodos de solução baseados em programação matemática para resolver instâncias baseadas no desastre na Região Serrana do Rio de Janeiro de 2011. Por outro lado, Alem et al. (2016) consideram decisões adicionais de pré-posicionamento de estoque e aquisição de suprimentos no mesmo problema. Duhamel et al. (2016) propõem um modelo matemático para a localização de facilidades e alocação de demanda às facilidades, além de heurísticas baseadas em decomposição para resolver o problema. Os métodos são testados com dados de desastres ocorridos na cidade de Belo Horizonte. Rebouças (2016) propõe modelos para a otimização de rotas de helicópteros e Xavier (2016) trata do planejamento da distribuição de suprimentos utilizando helicópteros. O primeiro testou o modelo proposto usando dados empíricos do desastre da Região Serrana do Rio de Janeiro em 2011, enquanto o segundo, usando dados do desastre do Vale de Itajaí em Santa Catarina de 2008.

Mais recentemente, Buzogany (2017) modela a convergência de materiais em situações de desastres utilizando dinâmica de sistemas e simulação, tendo como caso base as inundações ocorridas em São Luiz do Paraitinga em 2010. Maculan (2017) usa um modelo de programação linear que busca identificar as vias urbanas e hospitais que necessitam de alocação de recursos para melhorar a sua capacidade de atenção e o fluxo da população em caso de desastres. $\mathrm{O}$ objetivo é minimizar a quantidade de pessoas que não são atendidas nos hospitais por falta de capacidade. Para testar o modelo, os autores criam cenários para situações de desastres na cidade do Rio de Janeiro. Usando também dados de desastres no Rio de Janeiro, Moreno et al. (2018) propõem um modelo biobjetivo que considera a minimização de custos logísticos e a minimização do tempo de privação dos afetados. São abordadas decisões de localização de centros de auxílio, distribuição de suprimentos, dimensionamento da frota e alocação de demanda. Condeixa et al. (2017) consideram decisões de pré-posicionamento, localização e distribuição de suprimentos em um modelo de programação estocástica para minimizar os 
custos logísticos e uma penalidade por demanda insatisfeita. Os autores realizaram experimentos com o modelo usando dados de desastres no Vale do Paraíba em São Paulo.

Finalmente, observa-se que o número de trabalhos que tiveram interação com aplicações reais é relativamente baixo. Apenas Brito Jr. (2015) e Oliveira (2014) produziram estudos aplicados, por meio de parcerias com a Defesa Civil do Estado de São Paulo e o Corpo de Bombeiros da Cidade de Belo Horizonte, respectivamente. Oliveira (2014) desenvolveu modelos de simulação e otimização para as operações de atendimento à população afetada por fenômenos hidrológicos em Belo Horizonte pelo Corpo de Bombeiros. O trabalho de Brito Jr. (2015) tratou de decisões acerca de localização de depósitos para o pré-posicionamento de materiais utilizados no socorro a populações afetadas por desastres.

Cabe ressaltar que não foi encontrado nenhum trabalho sobre o desenvolvimento de ferramentas de suporte à decisão usando PO no contexto de logística humanitária.

\section{Caracterização do Problema e Modelagem}

Neste trabalho, dá-se enfoque ao planejamento envolvendo as fases de preparação e resposta em um evento de desastre. Para isso, é abordado o problema de localização e distribuição de suprimentos em operações de resposta a desastres, o qual combina quatro subproblemas: localização de centros de auxílio, dimensionamento da frota, transporte de produtos e alocação da demanda aos centros de auxílio, como proposto em Moreno et al. (2016). Os dois primeiros subproblemas são decisões de preparação, enquanto os dois últimos, decisões de resposta. Os subproblemas são detalhados na Subseção 3.1 e tratados de forma integrada em um modelo matemático proposto na Subseção 3.2.

\subsection{Descrição dos Subproblemas}

A relação entre os subproblemas envolvidos no contexto em estudo pode ser ilustrada utilizando-se uma rede estruturada, conforme apresentado na Figura 1.

Figura 1: Estrutura de rede mostrado a integração dos subproblemas.

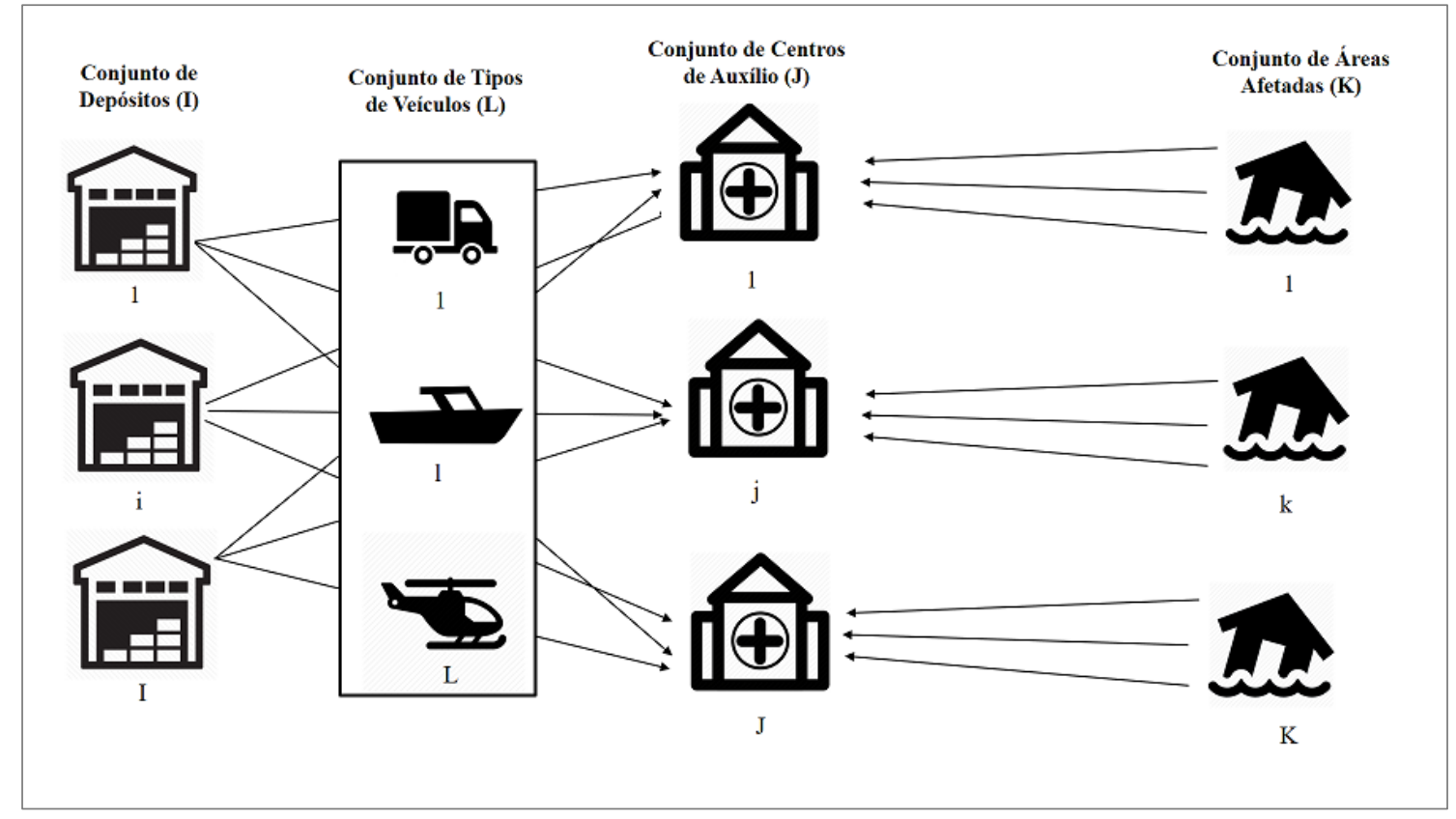

Fonte: Adaptado de Moreno (2015).

O subproblema de localização de centros de auxílio determina em qual das possíveis localidades operar esses centros, considerando que a demanda deve ser atendida pelos centros de auxílio abertos, os quais têm uma capacidade máxima (limitação física no volume) de 
armazenamento total e por produto. A capacidade por produto dos centros de auxílio indica que nem todos os centros têm capacidade para armazenar todos os tipos de produtos. Por exemplo, é possível que algum centro de auxílio não tenha refrigeração para manter alguns produtos com a qualidade requerida. Nesse caso, tais produtos não poderão ser enviados para esse centro.

Considera-se a existência de depósitos, cujas localizações são conhecidas a priori, e assume-se que estes não estão limitados por suas capacidades, mas sim pela disponibilidade dos suprimentos que armazenam. Podem existir estoques de produtos nos depósitos e nos centros de auxílio, sendo que nem toda a quantidade de produtos estocados nos centros permanece em condições de ser utilizada de um período para o outro devido ao impacto do desastre. Assume-se que os depósitos não são afetados pelo desastre e que os centros de auxílio abertos devem permanecer em funcionamento até o final das operações humanitárias. Essa consideração é motivada pelo fato de que o horizonte de planejamento é curto (dias ou blocos de horas) e o fechamento de centros de auxílio implica na mobilização de recursos, o que pode atrapalhar as operações humanitárias.

O subproblema de dimensionamento da frota envolve a decisão de determinar a quantidade e os tipos de veículos que devem ser contratados em cada depósito para distribuir os produtos aos centros de auxílio. Os veículos são contratados por período e a sua contratação não implica que sejam de fato utilizados no transporte de produtos.

O subproblema de transporte de produtos consiste em determinar a quantidade de cada tipo de produto que deve ser transportada dos depósitos até os centros de auxílio, que armazenam temporariamente os produtos demandados pelas áreas afetadas. Como já mencionado, há limitação de disponibilidade de produtos nos depósitos. Além disso, deve-se determinar em quais veículos deve-se realizar o transporte desses produtos, considerando que existe um conjunto de rotas que, como resultado do impacto do desastre, não estão disponíveis para alguns tipos de veículos. O número de produtos que podem ser transportados está limitado pela capacidade dos centros de auxílio (em volume) e pela capacidade dos veículos (em volume e peso). Na prática, como há produtos com características distintas, é importante que os meios de transporte considerem essas duas dimensões. Os veículos transitam entre o depósito e um único centro de auxílio e não são mais utilizados dentro de um mesmo período.

Finalmente, o subproblema de alocação da demanda consiste em designar uma fração da demanda de cada área afetada aos centros de auxílio, onde as vítimas podem se abastecer com os itens que necessitam. Assume-se um custo pelo atendimento da demanda que é proporcional à distância entre os centros de auxílio e as áreas afetadas. Tal custo é nulo se um centro de auxílio atende à demanda da mesma área onde está localizado. Este custo evita que as vítimas se desloquem a centros de auxílio afastados sempre que existam centros de auxílio mais próximos.

\subsection{Modelagem Matemática}

Os modelos de otimização aplicados à LH propostos na literatura consideram as diferentes fases e decisões do ciclo de gestão de desastres e podem ser classificados em determinísticos ou estocásticos. A maioria utiliza a programação estocástica, considerando diferentes cenários de desastres e suas probabilidades de ocorrência para determinar a melhor decisão a ser tomada (Moreno, 2015). Entretanto, modelos determinísticos podem ser úteis à realidade brasileira, especialmente para o desenvolvimento de uma ferramenta para uso com enfoque operacional. Segundo Alem et al. (2016) as práticas humanitárias no Brasil são mais reativas do que proativas. $\mathrm{O}$ aprovisionamento, por exemplo, costuma ocorrer alguns dias ou mais após o desastre, em áreas próximas ou mesmo afetadas pelo desastre, onde há escassez dos suprimentos necessários. Além disso, modelos determinísticos tipicamente requerem tempos computacionais menores para obtenção de soluções em relação aos modelos estocásticos, podendo ser mais adequados ao uso em situações de emergência.

O modelo proposto a seguir baseia-se no modelo de programação estocástica de Moreno et al. (2016). A modelagem proposta por tais autores aborda as duas fases mais críticas da gestão de desastres, preparação e resposta, de forma integrada. Além disso, considera múltiplos períodos, múltiplos produtos e múltiplos modais de transporte, levando em conta custos 
operacionais e sociais. Outra vantagem é que o modelo de Moreno et al. (2016) já foi validado com dados e estimativas do Megadesastre da Região Serrana do Rio de Janeiro de 2011.

Os subproblemas definidos na subseção anterior são tratados de forma integrada no modelo matemático proposto. A cada veículo é designada uma única viagem entre depósitos e centros de auxílio. Não se considera o tempo de viagem entre os nós. A notação matemática para definição do modelo é apresentada a seguir.

\section{Conjuntos}

- $W$ : Produtos transportados para os centros de auxílios.

- $D$ : Depósitos de onde partem as ajudas humanitárias.

- $J$ : Centros de auxílio.

- $K$ : Áreas afetadas pelo desastre.

- $L$ : Tipos de veículos disponíveis para fazer a distribuição dos produtos.

- $T$ : Períodos de tempo do horizonte de ajuda humanitária.

\section{Parâmetros}

- $c_{j}^{y}$ : Custo de operação do centro de auxílio $j$.

- $c_{i j l}^{v}$ : Custo de transporte do veículo $l$ no arco $(i, j)$.

- $c_{w}^{+}$: Custo de estoque do produto $w$.

- $c_{w}^{-}$: Penalidade por não satisfazer a demanda do produto $w$.

- $c_{k j}^{z}$ : Custos do centro de auxílio $j$ atender a demanda da área afetada $k$.

- $b_{w}\left(b_{w}^{\prime}\right)$ : Volume (peso) do produto $w$.

- $k_{l}^{v}\left(k_{l}^{\prime v}\right)$ : Capacidade em volume (peso) do veículo $l$.

- $k_{j}^{c}$ : Capacidade do centro auxílio $j$ (volume).

- $k_{i j l}^{a r c}$ : Número máximo de veículos do tipo $l$ que podem atravessar o $\operatorname{arco}(i, j)$.

- $q_{\text {wit }}$ : Suprimento de produtos $w$ no depósito $i$ no período $t$.

- $d_{w k t}$ : Demanda do produto $w$ na área afetada $k$ no período $t$.

- $u_{i j l t}$ : indica se a rota $(i, j)$ está disponível para ser percorrida pelo veículo do tipo $l$ no período $t\left(u_{i j l t}=1\right)$, ou não $\left(u_{i j l t}=0\right)$.

\section{Variáveis de decisão}

- $Y_{j t}$ : Indica se o centro de auxílio $j$ está em operação no período $t\left(y_{j t}=1\right)$, ou não $\left(y_{j t}=0\right)$.

- $P_{w i j l t}$ : Quantidade do produto $w$ transportada no arco $(i, j)$ pelo veículo $l$ no período $t$.

- $V_{i j l t}$ : Número de veículos do tipo $l$ utilizados no arco $(i, j)$ no período $t$.

- $Z_{w k j t}$ : Número de produtos $w$ entregues no centro auxílio $j$ para atendimento da área afetada $k$ no período $t$.

- $E_{w i t}$ : Quantidade de produtos $w$ estocados no depósito $i$ no período $t$.

- $I_{w j t}^{+}$: Quantidade de produtos $w$ estocados no centro de auxílio $j$ no período $t$.

- $I_{w j t}^{-}$: Quantidade de demanda insatisfeita do produto $w$ na área afetada $k$ no período $t$.

Definidos os parâmetros e as variáveis de decisão, apresenta-se a seguir o modelo de programação linear inteira-mista para localização e distribuição em operações logísticas humanitárias, proposto neste trabalho. 
$\min Z=\sum_{j \in D} \sum_{t \in T} c_{j}^{y} \cdot Y_{j t}+\sum_{i \in D} \sum_{j \in J} \sum_{l \in L} \sum_{t \in T} c_{i j l}^{v} \cdot V_{i j l t}+\sum_{w \in W} \sum_{k \in K} \sum_{j \in J} \sum_{t \in T} c_{k j}^{z} \cdot Z_{w k j t}+\sum_{w \in W} \sum_{j \in J} \sum_{t \in T} c_{w}^{+} \cdot I_{w j t}^{+}$
$\sum_{w \in W} \sum_{K \in k} \sum_{t \in T} c_{w}^{-} \cdot I_{w k t}^{-}$

sujeito a:

$$
\begin{aligned}
& \sum_{\mathrm{i} \in \mathrm{D}} \sum_{\mathrm{l} \in \mathrm{L}} P_{w i j l t}+I_{w j(t-1)}^{+}=\sum_{\mathrm{k} \in \mathrm{K}} Z_{w k j t}+I_{w j t}^{+}, \quad \forall w \in W, j \in J, t \in T, \\
& q_{w i t}+E_{w i(t-1)}=\sum_{\mathrm{j} \in \mathrm{J}} \sum_{\mathrm{l} \in \mathrm{L}} P_{w i j l t}+E_{w i t}, \quad \forall w \in W, i \in D, t \in T, \\
& I_{w k t}^{-}=d_{w k t}-\sum_{\mathrm{j} \in \mathrm{J}} Z_{w k j t}+I_{w k(t-1)}^{-}, \quad \forall w \in W, k \in K, t \in T, \\
& \sum_{\mathrm{w} \in \mathrm{W}} \sum_{\mathrm{i} \in \mathrm{D}} \sum_{\mathrm{l} \in \mathrm{L}} b_{w} \cdot P_{w i j l t}+\sum_{\mathrm{w} \in \mathrm{W}} b_{w} \cdot I_{w j(t-1)}^{+} \leq k_{j}^{c} \cdot Y_{j t}, \quad \forall j \in J, t \in T, \\
& V_{i j l t} \geq \frac{\sum_{w \in W} b_{w} \cdot P_{w i j l t}}{k_{l}^{v}}, \quad \forall i \in D, j \in J, l \in L, t \in T, \\
& V_{i j l t} \geq \frac{\sum_{w \in W} b_{w}^{\prime} \cdot P_{w i j l t}}{k_{l}^{\prime v}}, \quad \forall i \in D, j \in J, l \in L, t \in T, \\
& V_{i j l t} \leq k_{i j l}^{a r c} \cdot u_{i j l t}, \quad \forall i \in D, j \in J, l \in L, t \in T, \\
& Y_{j t} \leq Y_{j(t-1)}, \quad \forall j \in J, t \in T \\
& Y_{j t} \in\{0,1\}, \quad \forall j \in J, t \in T \\
& V_{i j l t} \geq 0 e i n t e i r o, \\
& P_{w i j l t}, Z_{w k j t}, I_{w j t}^{+}, I_{w k t}^{-}, E_{w i t} \geq 0, \quad \forall i \in D, j \in J, l \in L, t \in T, \\
& \forall w \in W, i \in D, j \in J, k \in K, l \in L, t \in T .
\end{aligned}
$$

A função objetivo (1) consiste em minimizar o custo total da operação, sendo, respectivamente, o custo de abertura dos centros de auxílio, o custo de transporte dos produtos entre depósitos e centros, custo de transporte de produtos entre centros e áreas, o custo de estoque nos centros de auxílio e o custo da demanda insatisfeita. As restrições (2) e (3) garantem a conservação do fluxo de produtos nos centros de auxílio e nos depósitos, respectivamente. As restrições (4) determinam a demanda insatisfeita (atraso) das áreas afetadas. Sem perda de generalidade, assume-se que os estoques e atrasos iniciais são nulos, i.e. $I_{w j 0}^{+}=I_{w k 0}^{-}=E_{w i 0}=0$. Note que a demanda insatisfeita de cada período é acumulada até o final das operações humanitárias ou até ser atendida.

As restrições (5) garantem que só pode existir transporte para um centro de auxílio se esse centro de auxílio estiver em operação $\left(Y_{j t}=1\right)$, e restringem o transporte e estoque de produtos nos centros de auxílio à sua capacidade total. Assim, a capacidade consumida pelos produtos transportados para um centro de auxílio mais a capacidade consumida pelos produtos que já estão no centro de auxílio deve ser menor ou igual à capacidade total do centro de auxílio. As restrições (6) e (7) determinam limitantes inferiores para o número de veículos necessários $\left(V_{i j l t}\right)$ para realizar o transporte de produtos dos depósitos aos centros de auxílio, respeitando as capacidades (peso e volume) dos veículos. O conjunto de restrições (8) garante que o veículo 1 só pode percorrer o arco $(i, j)$ no período $t$ se o arco estiver disponível $\left(u_{i j l t}=1\right)$. Estas restrições também limitam o número de veículos que podem ser utilizados à capacidade de transporte do arco $\left(k_{i j l}^{a r c}\right)$. Na maioria das situações práticas a capacidade de transporte nos arcos é 
considerado como um número suficientemente grande. As restrições (9) garantem que os centros de auxílio abertos permanecem em operação até o final das operações humanitárias. As restrições (10), (11) e (12) representam o domínio das variáveis de decisão.

\section{Implementação da Ferramenta de Apoio à Decisão}

O modelo proposto na seção anterior foi codificado usando a linguagem de modelagem algébrica GMPL (GNU Mathematical Programming Language), a qual é indicada para descrever modelos de programação matemática em interação com o software de otimização GLPK (GNU Linear Programming Kit, 2018), que é de código aberto e uso gratuito. A linguagem é um subconjunto da linguagem comercial AMPL, utilizada no software de modelagem que leva o mesmo nome. Em um primeiro momento, o modelo foi implementado em GMPL utilizando a interface do software GUSEK (2018), que também é de uso gratuito. A escolha da linguagem e dos softwares utilizados se deu pelo caráter gratuito e de uso livre, pois assim garante-se o uso da ferramenta em situações de desastre sem a necessidade de gastos adicionais com aquisição de software comercial.

Com a finalidade de obter uma ferramenta de apoio à decisão com interface intuitiva e amigável ao usuário, desenvolveu-se uma planilha eletrônica, baseada no modelo matemático e sua integração com os dados de entrada de uma possível instância real. Para isso, foi utilizado o Microsoft Excel, com apoio da linguagem de programação VBA (Visual Basic for Application) disponível de forma nativa no software, e um suplemento de otimização conhecido como SolverStudio (SolverStudio, 2018; Mason, 2013). Por meio deste suplemento é possível elaborar e resolver modelos de otimização, usando uma linguagem de modelagem algébrica, dentro do Microsoft Excel e de forma integrada aos dados da planilha. A Figura 2 ilustra a janela do Microsoft Excel com o modelo no suplemento SolverStudio (lateral direita) e os dados em uma aba na planilha.

A planilha eletrônica foi desenvolvida de modo a ser flexível e permitir ao usuário considerar as particularidades de diferentes situações. A ferramenta recebeu o nome de Loghum e sua versão atual possui um painel inicial com diferentes opções para o usuário, disponível na aba "Painel", conforme apresentado na Figura 3. No painel inicial, o usuário tem acesso a botões para as abas de entrada de dados de Produtos, Veículos, Áreas, Depósitos e Centros. Também nesse painel, encontra-se os botões "Criar Modelo" e "Limpar Modelo". O primeiro permite ao usuário gerar na aba "Modelo" as tabelas de entrada e saída de dados que são lidas pelo SolverStudio, enquanto o outro exclui todo o conteúdo da aba Modelo.

As abas específicas para a entrada de dados, por sua vez, recebem informações sobre as dimensões do modelo e os parâmetros associados a eles. Na aba "Produtos" (Figura 4), por exemplo, tem-se o código de cada produto que será distribuído às áreas afetadas e os parâmetros associados à dimensão do "Produto" como: descrição, número de afetados atendidos com uma unidade do produto por dia, seu volume em litros, sua massa em quilogramas $(\mathrm{Kg})$, custo de estoque (R $\$$ /unidade) e penalidade por demanda não atendida ( $\mathrm{R} \$$ unidade). A partir desses dados, a ferramenta gera tabelas intermediárias de forma automatizada, para permitir a combinação dos dados com o modelo matemático. O objetivo novamente é flexibilizar a aplicação para que a ferramenta possa ser utilizada com dados de diferentes instâncias de desastres. O usuário precisa apenas entrar com os dados do problema em cada uma das abas de entrada de dados e pressionar o botão "Criar Modelo" no painel inicial, para que a ferramenta crie automaticamente o conteúdo da aba "Modelo" com todas as tabelas usadas como dados de entrada para o modelo matemático. 
Figura 2: Implementação do modelo no Microsoft Excel usando o SolverStudio.

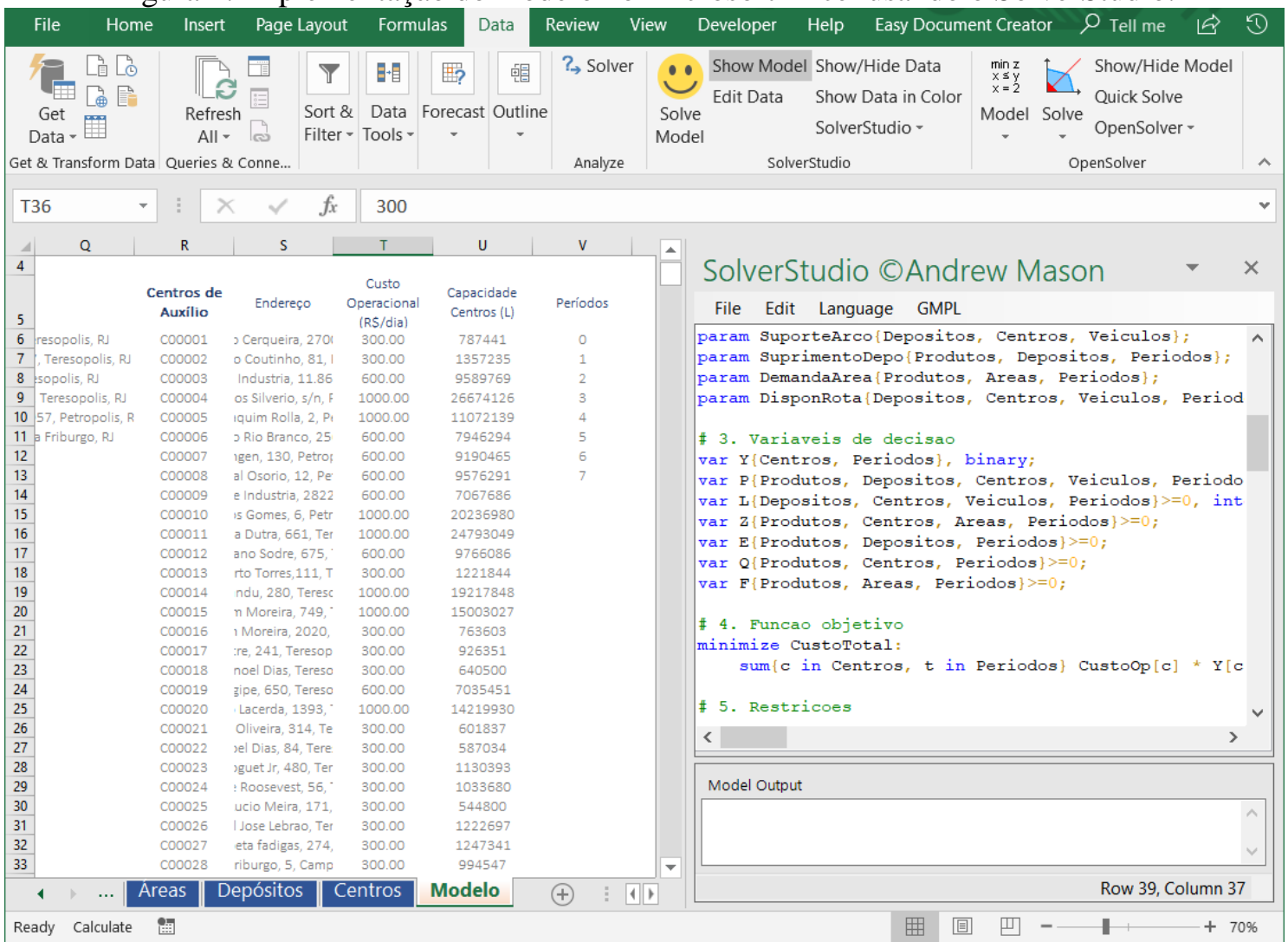

Fonte: Elaborada pelos autores.

Figura 3: Tela inicial da ferramenta Loghum.

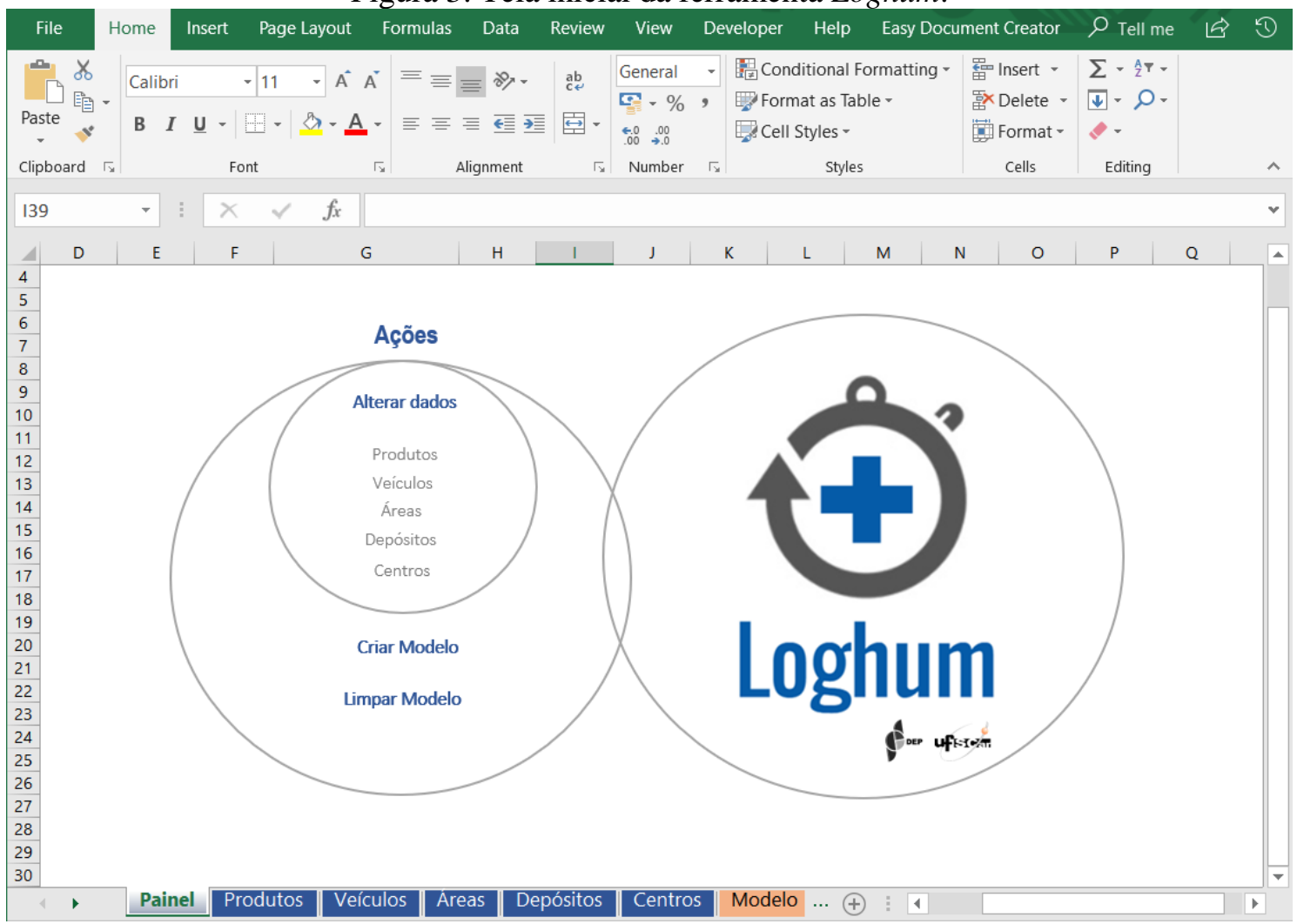

Fonte: Elaborada pelos autores. 
$\mathrm{Na}$ aba "Modelo" é apresentada a janela do SolverStudio, na lateral direita, onde o código em GMPL está inserido (ver Figura 2). O usuário não precisa interagir com essa janela, exceto se quiser realizar alguma alteração no código do modelo. Ao clicar no botão "Solve Model", no canto superior direito da barra de ferramentas do Microsoft Excel, o GLPK é acionado e abastecido com os dados da planilha. Após o processamento por métodos de otimização para problemas de Programação Linear e Programação Inteira-Mista do GLPK, a solução é impressa nas tabelas de saída de dados, também localizadas na aba "Modelo". Na implementação, são mantidos os parâmetros default do GLPK, podendo o usuário modificar o tempo máximo de execução (parâmetro tmlim) e a tolerância de otimalidade (parâmetro mipgap) por meio dos campos indicados na aba Modelo.

A ferramenta desenvolvida é de código aberto, uso livre e está disponível publicamente no endereço http://www.dep.ufscar.br/docentes/munari/loghum. Pode ser usada na resolução de problemas de localização e distribuição de suprimentos em operações de resposta a desastres, bem como estendida para outros tipos de situações em logística humanitária.

Figura 4: Aba para entrada de dados sobre os produtos.

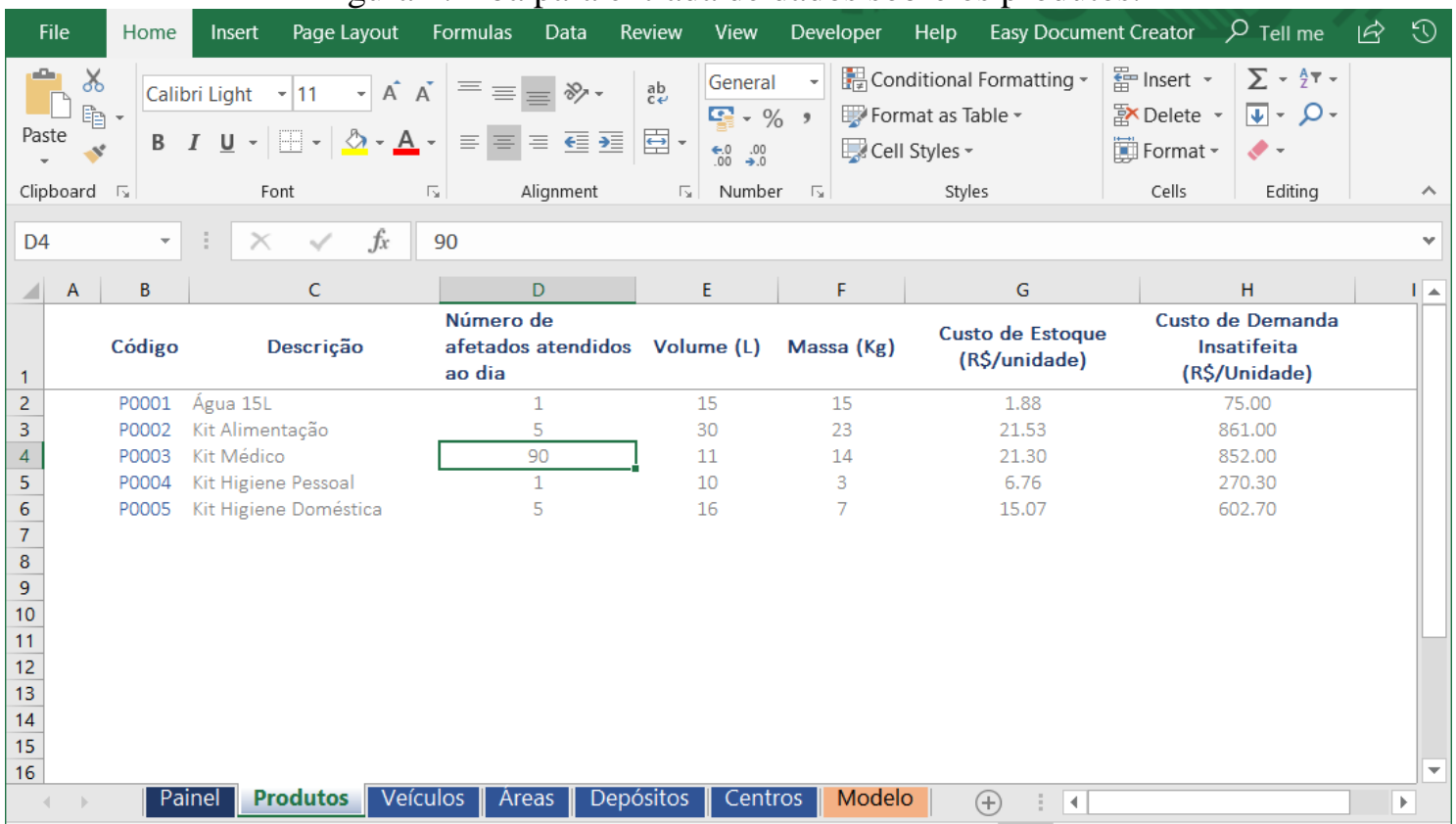

Fonte: Elaborada pelos autores.

\section{Resultados}

A funcionalidade da ferramenta proposta foi avaliada inicialmente com instâncias fictícias de pequeno porte, geradas aleatoriamente pelos autores, com base em valores com ordem de grandeza condizentes com parâmetros do caso real a ser abordado mais à frente neste texto. O objetivo foi realizar testes com a implementação computacional realizada. Após essa etapa, foram usados dados e estimativas de um desastre natural, súbito e de nível II, que ocorreu na Região Serrana do Rio de Janeiro em 2011 (Busch e Amorim, 2011). A caracterização dos dados usados é apresentada na Subseção 5.1. A análise dos resultados obtidos pela ferramenta é feita na Subseção 5.2. Todo os testes foram executados em uma máquina com processador Intel Core i5-7200 2.71 GHz, 8.0 GB de RAM e sistema operacional Windows 10. Para os testes, definiu-se a tolerância de otimalidade (gap) do software GLPK igual a $0,01 \%$, por meio do parâmetro mipgap, disponível na Tabela GMPLOptions da aba "Modelo" disponível na ferramenta. 


\subsection{Caracterização dos Dados do Caso em Estudo}

Segundo informações disponíveis no relatório Banco Mundial (2012), chuvas intensas durante os dias de 11 e 12 de janeiro, somadas à ocupação irregular do solo causaram inundações e deslizamentos, levando a 905 mortes e afetando 300 mil pessoas, $42 \%$ da população dos municípios atingidos. Areal, Bom Jardim, Nova Friburgo, São José do Vale do Rio Preto, Sumidouro, Petrópolis e Teresópolis decretaram estado de calamidade pública (ECP) e mais outros nove municípios foram afetados.

De acordo como o mesmo relatório, uma vez que diferentes entidades e instituições atuaram nas operações humanitárias, a coleta e compatibilização de dados se mostrou um grande desafio. Consequentemente, apesar dos dados usados como entrada para o modelo serem suficientes para retratar a magnitude e o alcance do desastre, estes provêm de fontes distintas, não necessariamente compatíveis, e devem ser consideradas com cautela.

As tabelas com os dados utilizados em testes computacionais com a ferramenta podem ser visualizadas no Apêndice deste artigo e a origem dos mesmos é apresentada a seguir:

- Produtos. Cinco tipos de suprimentos são considerados (Tabela A1), cujas informações sobre número de afetados atendidos por unidade do produto, custos de estoque e de atraso, massa e volume foram baseadas nos trabalhos de Alem et al. (2016) e Rawls e Turnquist (2010);

- Veículos. Utilizou-se três tipos de veículos: caminhão semi-pesado, barco e helicóptero tipo esquilo (Tabela A2). Suas capacidades em massa e volume, além do custo de operação em reais por quilômetro seguem o trabalho de Moreno (2015);

- Áreas. Consideram-se sete áreas afetadas (Tabela A3), correspondentes às sete cidades que decretaram estado de calamidade pública e cuja informação sobre o número de afetados é apresentada no relatório do Banco Mundial (2012);

- Depósitos e centros. São usados seis depósitos (Tabela A4) e 40 centros de auxílio potenciais (Tabela A5). Suas localizações foram obtidas do estudo de Bataglin e Alem (2014), que se basearam em informações fornecidas pela Promotoria de Justiça da Cidade de Teresópolis cruzadas com informações sobre centros de coleta disponibilizados no site da Cruz Vermelha e prefeitura de cidades afetadas;

- Capacidade dos centros. Os centros de auxílio foram considerados como pequenos (prefeituras, igrejas e secretarias), grandes (sedes dos bombeiros e da defesa civil) e médios (demais prédios) e suas capacidades foram determinadas usando uma distribuição uniforme a partir do tamanho médio de cada tipo.

- Demanda. Para cada produto $w$, período $t$ e área $k$, multiplica-se o número total de afetados dessa área (Tabela A3) por um número aleatório gerado por uma distribuição uniforme no intervalo $[0,8 ; 1,2]$. $\mathrm{O}$ valor resultante é dividido pelo número de afetados atendidos por uma unidade do produto $w$ (Tabela A1), resultando da demanda $d_{w k t}$.

- Custos de transporte. Determinado pelo produto da distância entre os depósitos e centro de auxílio (fornecida pelo Google Maps®) e o custo de operação de cada veículo.

- Custo de atendimento. Esse custo penaliza a localização de centros distantes das áreas afetadas. Foi considerado proporcional à distância entre o centro de auxílio e as áreas afetadas (fornecida pelo Google Maps ${ }^{\circledR}$ ), usando-se um fator multiplicador de 0,01.

- Capacidade dos arcos. Considerou-se um máximo de 300 veículos para cada arco, seguindo os trabalhos de Bataglin e Alem (2014) e Moreno (2015);

- Suprimento dos depósitos. A disponibilidade de cada produto $w$ no depósito $i$, em cada período $t$, é calculada usando o número total de afetados (considerando todas as áreas afetadas), multiplicado por um número aleatório gerado usando uma distribuição uniforme no intervalo $[0,7 ; 1,3]$. Esse valor é então dividido pelo número de afetados atendidos por uma unidade do produto $w$ (Tabela A1) e pelo número de depósitos, resultando em $q_{\text {wit }}$. Assim, o total de suprimentos disponiveis é dividido entre todos os depósitos. 
- Disponibilidade de rota. Uma vez que os relatórios sobre o desastre não fornecem nenhuma informação conclusiva sobre indisponibilidade de rotas, as mesmas foram todas consideradas disponíveis.

\subsection{Análise da Ferramenta}

Os experimentos computacionais apresentados nesta seção têm o intuito de verificar a usabilidade e o comportamento da ferramenta Loghum, ao ser utilizada com dados da situação real de um desastre, descrito na subseção anterior. A mesma instância foi executada várias vezes considerando-se diferentes números de períodos, a saber 1, 3, 5, 7 e 10 períodos, de modo a analisar o desempenho da ferramenta em relação ao horizonte de tempo. Operações de distribuição planejadas em um horizonte de tempo maior do que 10 dias acabam carregando uma incerteza muito grande.

A Tabela 3 apresenta, para cada um dos horizontes de planejamento considerados, o custo total da solução obtida; a penalidade por atraso (demanda insatisfeita nas áreas afetadas) e o custo logístico total, acompanhados do percentual de cada tipo de custo na função objetivo; e o tempo gasto para resolver o problema. A penalidade por atraso se refere ao custo por atraso de produtos nas áreas afetadas, enquanto o custo logístico é a soma dos custos de operação dos centros de auxílio, transporte de produtos, estoque e atendimento da demanda. Tanto o custo total, quanto o tempo de processamento, aumentam ao considerar mais períodos no horizonte de planejamento. O tempo gasto no processamento das instâncias consideradas se mostram relativamente curtos e atrativos ao usuário.

Tabela 3: Custo total, penalidade por demanda insatisfeita, custo logístico total e tempo de resolução para os diferentes horizontes de planejamento considerados.

\begin{tabular}{|c|c|c|c|c|c|c|}
\hline \multirow{2}{*}{$\begin{array}{l}\text { Número de } \\
\text { períodos }\end{array}$} & \multirow{2}{*}{$\begin{array}{c}\text { Custo } \\
\text { total }\end{array}$} & \multicolumn{2}{|c|}{ Penalidade atraso } & \multicolumn{2}{|c|}{ Custo logístico } & \multirow{2}{*}{$\begin{array}{c}\text { Tempo } \\
\text { (seg.) }\end{array}$} \\
\hline & & Valor & $\%$ do total & Valor & $\%$ do total & \\
\hline 1 & $5.714 .418,89$ & $5.447 .375,90$ & 95,33 & $267.042,99$ & 4,67 & 8,60 \\
\hline 3 & $34.233 .121,91$ & $33.510 .269,45$ & 97,89 & $722.852,46$ & 2,11 & 46,20 \\
\hline 5 & $73.344 .846,21$ & $72.123 .079,53$ & 98,33 & $1.221 .766,67$ & 1,67 & 103,60 \\
\hline 7 & $222.554 .081,59$ & $221.757 .477,35$ & 99,64 & $796.604,24$ & 0,36 & 167,00 \\
\hline 10 & $399.512 .565,86$ & $397.041 .807,35$ & 99,38 & $2.470 .758,51$ & 0,62 & 394,80 \\
\hline
\end{tabular}

Fonte: Elaborada pelos autores.

Note que o custo mais significativo na função objetivo é a penalidade por demanda insatisfeita, o qual representa mais de $95 \%$ do custo total. Esse resultado é consequência do fato de que a falta de produtos nas áreas afetadas é penalizada com um valor alto em relação aos demais custos. A ideia dessa penalidade ser alta é evitar que as pessoas nas áreas afetadas sofram pela falta de produtos por causa de poupar custos logísticos. Em geral, observou-se que ao aumentar o número de períodos de operações humanitárias existe um aumento na penalidade total por demanda insatisfeita que é consequência do aumento da demanda nas áreas afetadas ao considerar mais dias no horizonte de planejamento. Esse fato reflete cenários reais, nos quais se observa que quanto mais dias são considerados, mais vítimas surgem com necessidade de suprimentos. A penalidade por atraso mostra que algumas das pessoas com necessidades nas áreas afetadas sofrem com a falta de produtos, pois existe demanda que nem sempre pode ser atendida seja por causa de falta de suprimentos nos depósitos ou por falta de capacidade do sistema logístico para responder ante essa demanda. A falta de suprimento nos depósitos é comum em situações de pós-desastre, pois nem sempre as doações ou recursos das entidades de apoio são suficientes para a compra de todos os suprimentos necessários ou para a implementação de uma infraestrutura logística (veículos disponíveis, capacidade dos centros de auxílio, etc.) suficientemente efetiva.

O custo logístico também aumenta ao considerar mais dias no horizonte de planejamento, pois as operações de distribuição, estoque e atendimento devem ser realizadas para um maior número de vítimas que surgem a cada dia. Os custos logísticos mais representativos são o custo 
de atendimento da demanda e o custo de transporte, como pode ser observado na Figura 5. A Figura 5 mostra o percentual de cada tipo de custo logístico (operação dos centros, transporte, estoque, atendimento) dentro do custo logístico total.

Figura 5: Percentual de cada tipo de custo logístico dentro do custo logístico total.

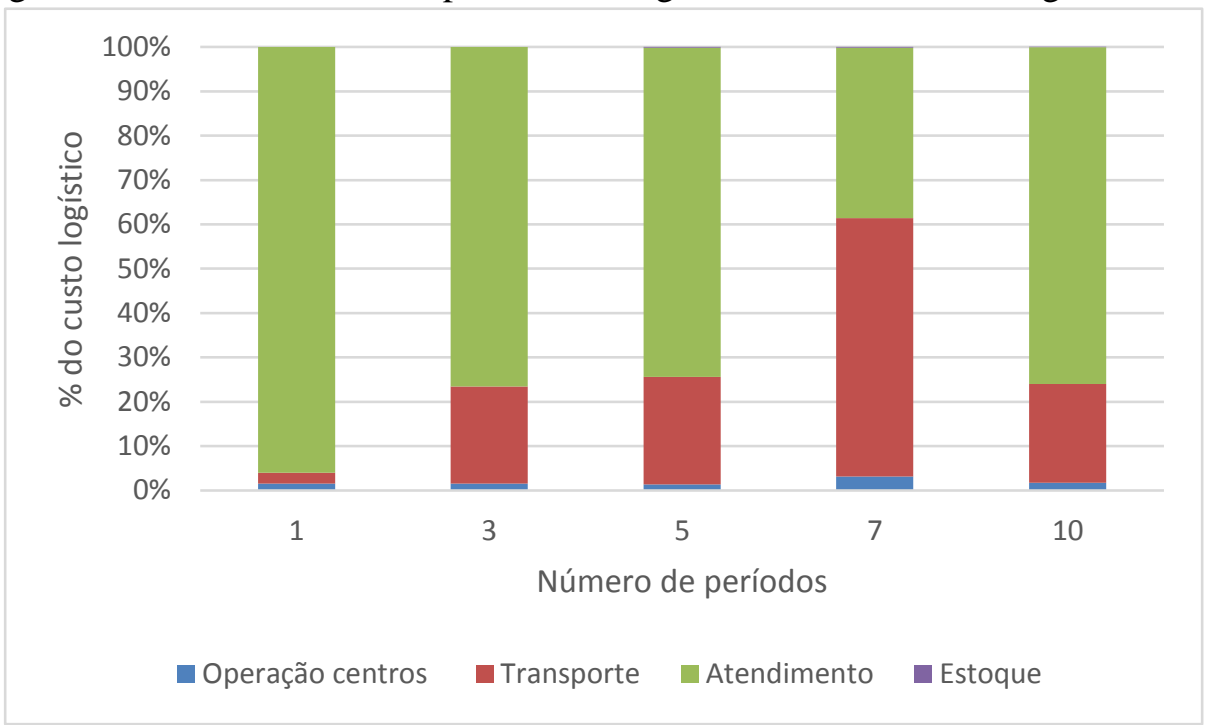

Fonte: Elaborada pelos autores.

Note na Figura 5 que o custo de atendimento da demanda junto com o custo de transporte representam mais de $90 \%$ dos custos logísticos totais. Por outro lado, o custo de operação dos centros representa menos de $3 \%$ dos custos logísticos enquanto o custo de estoque é quase que marginal em relação aos demais custos. De fato, o estoque de produto é muito baixo e apenas considerado nos horizontes de planejamento com mais número de períodos, como pode ser observado na Tabela 4, que sumariza algumas das principais decisões do problema, a saber: o número de centros de auxílio abertos; o número de viagens realizadas por cada tipo de veículo (V1-caminhão, V2-barco, V3-helicóptero); a quantidade de produtos estocados; e o nível de serviço. O nível de serviço é definido como a proporção de demanda insatisfeita (produtos atrasados) em relação à demanda total.

Tabela 4: Principais decisões do problema.

\begin{tabular}{|c|c|c|c|c|c|c|}
\hline \multirow{2}{*}{$\begin{array}{l}\text { Número de } \\
\text { períodos }\end{array}$} & \multirow{2}{*}{$\begin{array}{l}\text { Centros } \\
\text { abertos }\end{array}$} & \multicolumn{3}{|c|}{ \# viagens dos veículos } & \multirow{2}{*}{$\begin{array}{l}\text { Quantidade } \\
\text { de estoque }\end{array}$} & \multirow{2}{*}{$\begin{array}{c}\text { Nível de } \\
\text { serviço (\%) }\end{array}$} \\
\hline & & $\mathrm{V} 1$ & $\mathrm{~V} 2$ & V3 & & \\
\hline 1 & 6 & 1143 & 2 & 4 & 0 & 98,26 \\
\hline 3 & 10 & 3505 & 0 & 11 & 0 & 98,91 \\
\hline 5 & 10 & 5895 & 0 & 21 & 102 & 96,97 \\
\hline 7 & 12 & 8516 & 1 & 24 & 154 & 97,47 \\
\hline 10 & 12 & 11945 & 5 & 73 & 68 & 98,88 \\
\hline
\end{tabular}

Fonte: Elaborada pelos autores.

Note que, diferente da penalidade por atraso, que aumenta ao considerar mais períodos no horizonte do planejamento, o nível de serviço se mantém similar para as diferentes instâncias. Isso indica que para os diferentes horizontes de planejamento considerados, em proporção, é atendido o mesmo percentual de demanda. Para todas as instâncias, o nível de serviço é maior que $96 \%$, o que é um valor relativamente alto considerando-se que nem sempre todos os suprimentos necessários estão disponíveis para o atendimento das vítimas. É importante ressaltar que os veículos mais usados são os caminhões, seguido dos helicópteros e os barcos. Os caminhões são os veículos com o melhor custo-benefício, pois possuem uma capacidade relativamente alta e custo relativamente baixo. Os barcos, por outro lado, são veículos também com custo relativamente baixo, mas a sua capacidade é baixa. Além disso, são poucos os arcos 
(depósito-centro) em que podem ser usados os barcos em relação aos arcos em que podem ser usados os caminhões. Os helicópteros, por outro lado, podem ser usados na maioria dos arcos, mas são veículos muito caros, cujo uso é justificado apenas em casos em que os arcos não estão disponíveis para os outros modais de transporte.

No total, na instância que considera um único período, foram abertos 6 centros de auxílio enquanto nas demais instâncias o número de centros de auxílio abertos variou entre 10 e 12 . Nota-se que apenas um quarto dos centros de auxílio são necessários para realizar a distribuição dos suprimentos. Os centros de auxílio foram alocados, em geral, nas cidades com maior número de afetados. Para o horizonte de planejamento com um período, por exemplo, foram alocados dois centros em Nova Friburgo e outros dois em Teresópolis, sendo as cidades com o maior número de afetados. Petrópolis e Sumidoro receberam um centro de auxílio cada. As outras cidades não receberam centros de auxílio, pois os custos de transporte desde os depósitos para centros localizados nessas áreas são maiores que os custos de atendimento da demanda dessas áreas desde cidades vizinhas. Note que à medida que a demanda aumenta considerando mais períodos no horizonte de planejamento, torna-se viável a localização de depósitos em cidade com um número proporcionalmente menor de pessoas afetadas.

Em resumo, os resultados obtidos se mostraram coerentes com a proposta do modelo e puderam ser obtidos e analisados de forma rápida e intuitiva por meio da ferramenta Loghum. A aplicação da ferramenta a outros casos deve possibilitar uma avaliação mais precisa e aprofundada de sua adequação a situações reais de desastre.

\section{Conclusão}

O número de desastres naturais que ocorrem no planeta cresce a cada ano. O Brasil, apesar de considerado por muitos, menos propenso a desastres naturais por sua geomorfologia e condições climáticas privilegiadas, é o pais americano com o maior número de afetados por desastres nos últimos 35 anos. Isso se deve ao pouco preparo do país para lidar com esse tipo de situação e a vulnerabilidade social e econômica da maioria da população. Dessa forma, identifica-se a necessidade do desenvolvimento de mais trabalhos abordando a gestão de desastres no cenário nacional, principalmente de forma quantitativa. As ações em logística humanitária (LH) envolvem desafios devido ao caráter de urgência, ambiente instável, demandas flutuantes e com alto nível de incerteza, estoques de suprimentos incertos e grande necessidade de coordenação de vários atores envolvidos no desastre. A pesquisa operacional (PO), por buscar a otimização do processo de tomada de decisão em situações complexas, se configura como ferramenta atrativa para dar suporte à decisão nos processos de LH.

A quantidade de estudos que tratam da aplicação da PO no planejamento e execução de operações de LH tem aumentado nos últimos anos no cenário brasileiro. Os autores têm apresentado modelos matemáticos que suportam as decisões de aprovisionamento de suprimentos emergenciais, localização de depósitos e centros de auxílio, transporte e distribuição de suprimentos, evacuação de vítimas e alocação de pessoal. Existem modelos que integram esses diferentes tipos de decisões, o que é muito útil para que estes sejam aderentes a situações reais; porém, tais modelos ainda representam uma proporção pequena do total. A fração de estudos que culminam em modelos empíricos ou aplicados ainda é pequena.

A ferramenta de apoio à decisão apresentada neste trabalho tem o intuito de contribuir com a aplicação de modelos e métodos da PO em situações abordadas pela LH. O modelo matemático proposto e integrado à ferramenta busca auxiliar nas fases de preparação e resposta de desastres integrando as decisões de localização de centros de auxílio, distribuição de suprimentos, dimensionamento de frota e alocação de demanda aos centros. A ferramenta é de código aberto e uso livre, podendo ser usada no apoio a situações de desastre que envolvam as decisões citadas, bem como estendida a outros contextos. Pela simplicidade da ferramenta, é possível que ela seja utilizada por especialistas em treinamentos e simulações de diversos tipos de desastres no território nacional. Além disso, a integração da ferramenta com outros sistemas de informação, como GIS e GPS, pode ajudar a fornecer dados de entrada mais precisos e em tempo real, evitando-se a necessidade de utilizar cenários históricos, como comumente 
considerado na literatura. Nesse sentido, os tempos computacionais poderiam ser reduzidos e, mesmo instâncias de grande porte, resolvidas em um tempo plausível.

Como trabalhos futuros, seria interessante integrar a ferramenta com métodos de solução específicos, como heurísticas e metaheurísticas, e outros softwares de otimização para resolver as instâncias práticas mais eficientemente (Moreno et al., 2017a). Além disso, pretende-se realizar melhorias na ferramenta de forma a garantir que se adeque a diferentes situações. Para que o modelo apresente maior aderência às situações reais é preciso testá-lo com dados de outros tipos de desastres brasileiros e estendê-lo para considerar outras especificidades do processo de tomada de decisão de gestão de desastres. Parece fundamental realizar esse tipo de trabalho em melhor sintonia com órgãos e instituições responsáveis pelas operações humanitárias, como a Defesa Civil, para realizar mais testes computacionais e obter feedbacks que sejam, de fato, úteis na aplicação do modelo matemático e da ferramenta na prática. Houve tentativas de cooperação com estes órgãos para realizar esse trabalho. Cinco órgãos da Defesa Civil foram contatados por e-mail e não houve nenhuma resposta. Apesar de não ter sido possível obter dados empíricos de outros casos reais por meio desses contatos, existe a possibilidade de uma parceria futura com outros pesquisadores, permitindo assim a melhoria da ferramenta. A planilha está disponível para os demais pesquisadores que queiram usá-la e contribuir com sua melhoria.

Agradecimentos. Os autores agradecem aos revisores anônimos pelas sugestões que certamente contribuíram para a melhoria deste artigo. Além disso, agradecem o apoio da Fundação de Amparo à Pesquisa do Estado de São Paulo (FAPESP) - processos 16/23366-9, 16/15966-6 e 15/26453-7 - e Conselho Nacional de Desenvolvimento Científico e Tecnológico (CNPq).

\section{Referências}

Alcántara-Ayala, I. Geomorphology, natural hazards, vulnerability and prevention of natural disasters in developing countries. Geomorphology, v. 47, n. 2-4, p. 107-124, 2002.

Alem, D., Bektas, T. e Clark, A. Incorporating vulnerabilities into disaster relief planning: Insights from multiobjective optimisation. Working Paper, 2017.

Alem, D., Clark, A. e Moreno, A. Stochastic Network Models for Preparedness and Response in Disaster Relief. European Journal of Operational Research, v. 255, n. 1, p. 187-206, 2016.

Altay, N. e Green III, W. G. OR/MS research in disaster operations management. European Journal of Operational Research, v. 175, n. 1, p. 475-493, 2006.

Balcik, B., Beamon, B. M., Krejci, C. C., Muramatsu, K. M. e Ramirez, M. Coordination in humanitarian relief chains: Practices, challenges and opportunities. International Journal of Production Economics, v. 126, n. 1, p 22-34, 2010.

Banco Mundial. Avaliação de Perdas e Danos: Inundações e Deslizamentos na Região Serrana do Rio de Janeiro - Janeiro de 2011. Relatório 73623. 2012. Disponível em: http://documents.worldbank.org/curated/en/260891468222895493/pdf/NonAsciiFileName0.pdf. Acesso em: 01/11/2017.

Bataglin, L. e Alem, D. O problema de localização-distribuição no megadesastre da Região Serrana no Rio de Janeiro. Gestão \& Produção, v. 21, n. 4, p. 865-881, 2014.

Bertazzo, T. R. Mecanismos de coordenação em gestão de operações humanitárias: proposição de um modelo conceitual de simulador e de jogo logístico humanitário. $148 \mathrm{f}$. Dissertação 
(Mestrado em Engenharia de Transportes) - Escola Politécnica, Universidade de São Paulo, São Paulo-SP, 2014.

Brito Jr., I. Localização de depósitos de suprimentos de alivio para resposta a desastres através de programação linear estocástica e análise de decisão com múltiplos critérios. $233 \mathrm{f}$. Tese (Doutorado em Engenharia de Produção) - Escola Politécnica, Universidade de São Paulo, São Paulo-SP, 2015.

Busch, A. e Amorim, S. A tragédia da região serrana do Rio de Janeiro em 2011: procurando respostas. 2011. Disponível em: http://repositorio.enap.gov.br/handle/1/328. Acesso em: 01/11/2017.

Buzogany, R. F. Modelagem da convergência de materiais em desastres por meio de dinâmica de sistemas. 108 f. Dissertação (Mestrado em Engenharia de Produção) - Escola Politécnica, Universidade de São Paulo, São Paulo-SP, 2017.

Cavalcanti, L. B. Coordenação da entrega de ajuda a vítimas de desastre: uma abordagem multicritério com pensamento focado em valor. 123 f. Dissertação (Mestrado em Engenharia de Produção) - Escola Politécnica, Universidade de São Paulo, São Paulo-SP, 2015.

Chang, S. E. e Falit-Baiamonte, A. Disaster vulnerability of businesses in the 2001 Nisqually earthquake. Global Environmental Change Part B: Environmental Hazards, v. 4, n. 2, p. 59-71, 2002.

Condeixa, L., Leiras, A., Oliveira, F. e De Brito Jr., I. Disaster relief supply pre-positioning optimization: A risk analysis via shortage mitigation. International Journal of Disaster Risk Reduction, v. 25, p. 238-247, 2017.

De Loyola Hummell, B. M., Cutter, S. L. e Emrich C. T. Social vulnerability to natural hazards in Brazil. International Journal of Disaster Risk Science, v. 7, n. 2, p. 111-122, 2016.

Duhamel, C., Santos, A. C., Brasil, D., Châtelet, E. e Birregah, B. Connecting a population dynamic model with a multi-period location-allocation problem for post-disaster relief operations. Annals of Operations Research, v. 247, n. 2, p. 693-713, 2016.

EM-DAT - Emergency Events Database. The international disaster database. 2018. Disponível em: https://www.emdat.be/emdat_db/. Acesso em: 23/06/2018.

Feltrin, T. F. Procedimentos para gestão de ocorrência de inundações em cidade de pequeno e médio portes com o uso de SIG e logística humanitária. Estudo de caso: cidade de Jahu, SP. 244 f. Dissertação (Mestrado em Engenharia Urbana) - Centro de Ciências Exatas e de tecnologia, Universidade Federal de São Carlos, São Carlos-SP, 2014.

GNU Linear Programming Kit: software livre. Versão 4.6. 2018. Andrew Makhorin, Department for Applied Informatics, Moscow Aviation Institute, Moscow, Russia. Disponível em: http://www.gnu.org/software/glpk/. Acesso em: 01/06/2018.

GUSEK (GLPK Under Scite Extended Kit). Versão 0.2. 2018. Luiz Bettoni. Disponível em: http://gusek.sourceforge.net. Acesso em: 01/06/2018.

Kobiyama, M., Mendonça, M., Moreno, D., Marcelino, I., Marcelino, E., Gonçalves, E., Brazetti, L., Goerl, R., Molleri, G. e Rudorff, F. Prevenção de desastres naturais: Conceitos básicos. Curitiba-PR: Editora Organic Trading, 2006. 
Lima, F. S. Logística humanitária: modelagem de processos para a fase de aquisição na resposta a desastres naturais. 233 f. Tese (Doutorado em Engenharia de Produção) - Centro Tecnológico, Universidade Federal de Santa Catarina, Florianópolis-SC, 2014.

Lima, F. S., Oliveira, D. e Gonçalves, M. B. Seleção de fornecedores para atendimento às vítimas de desastres naturais considerando o lead time logístico dos produtos na fase de aquisição. Journal of Transport Literature, v. 9, n. 1, p. 10-14, 2015.

Maculan, G. Modelo de programação linear para alocar recursos em vias e hospitais em caso de desastres. 82 f. Dissertação (Mestrado em Engenharia de Produção) - Departamento de Engenharia Industrial, Pontifícia Universidade Católica do Rio de Janeiro, Rio de Janeiro-RJ, 2017.

Mason, A. J. SolverStudio: A new tool for better optimisation and simulation modelling in Excel. INFORMS Transactions on Education, v. 14, n. 1, p. 45-52, 2013.

Moreno, A. Localização de centros de auxílio e distribuição de suprimentos em operações de respostas a desastres. Dissertação (Mestrado em Engenharia de Produção) - Centro de Ciências e Tecnologias para a Sustentabilidade, Universidade Federal de São Carlos, Sorocaba-SP, 2015.

Moreno, A., Alem, D. e Ferreira, D. Heuristic approaches for the multiperiod locationtransportation problem with reuse of vehicles in emergency logistics. Computers \& Operations Research, v. 69, p. 79-96, 2016.

Moreno, A., Alem, D. e Ferreira, D. Localização de centros de auxílio e distribuição de suprimentos em operações de resposta a desastres. Transportes, v. 25, n. 2, p. 118-136, 2017 a.

Moreno, A., Alem, D., Ferreira, D. e Clark, A. An effective two-stage stochastic multi-trip location-transportation model with social concerns in relief supply chains. European Journal of Operational Research, v. 269, n. 3, p. 1050-1071, 2018.

Moreno, A., Ferreira, D. e Alem, D. A bi-objective model for the location of relief centers and distribution of commodities in disaster response operations. DYNA, v. 84, n. 200, p. 356-366, $2017 \mathrm{~b}$.

Nogueira, C. W. O enfoque da logística humanitária na localização de uma central de inteligência e suporte para situações emergenciais e no desenvolvimento de uma rede dinâmica. 273 f. Tese (Doutorado em Engenharia de Produção) - Centro Tecnológico, Universidade Federal de Santa Catarina, Florianópolis-SC, 2010.

Nogueira, C. W., Gonçalves, M. B. e Novaes, A. G. Logística humanitária e logística empresarial: Relações, conceitos e desafios. In: Anais do XXI Congresso de Ensino e Pesquisa em Transportes, Rio de Janeiro. ANPET, 2007.

Oliveira, A. Simulação dos serviços de atendimento aos efeitos gerados pelos fenômenos hidrológicos mais recentes em Belo Horizonte. Dissertação (Mestrado em Engenharia de Produção) - Escola de Engenharia, Departamento de Engenharia de Produção, Universidade Federal de Minas Gerais, Belo Horizonte-MG, 2014.

Rawls, C. G. e Turnquist, M. A. Pre-positioning of emergency supplies for disaster response. Transportation Research Part B: Methodological, v. 44, n. 4, p. 521-534, 2010.

Rebouças, S. Otimização de rotas de helicópteros de resgate em desastres naturais. Dissertação (Mestrado em Engenharia Aeronáutica e Mecânica) - Instituto Tecnológico de Aeronáutica, São 
José dos Campos-SP, 2016.

SolverStudio: SolverStudio for Excel. Versão 0.09.03. 2018. Andrew Mason. Disponível em: http://www.solverstudio.org. Acesso em: 01/06/2018.

Tomasini, R. e Van Wassenhove, L. Humanitarian logistics. New York, NY: Palgrave Macmillan, 2009.

UNISDR - United Nations Office for Disaster Risk Reduction. Terminology. 2007. Disponível em: https://www.unisdr.org/we/inform/terminology. Acesso em: 01/05/2016.

UNISDR - United Nations Office for Disaster Risk Reduction. The human cost of weather related disasters. 2015. Disponível em: http://www.unisdr.org/2015/docs/climatechange/ COP21_WeatherDisastersReport_2015_FINAL.pdf. Acesso em: 01/05/2016.

Xavier, I. Procedimento para Planejamento do Emprego de Helicópteros no Transporte Aéreo Logístico em Desastres Naturais. Dissertação (Mestrado em Engenharia de Transportes), Instituto Militar de Engenharia, Rio de Janeiro, 2016. 


\section{Apêndice - Dados da Instância Região Serrana do Rio}

Tabela A1: Características dos produtos.

\begin{tabular}{|c|c|c|c|c|c|}
\hline Produtos & $\begin{array}{c}\text { Número de } \\
\text { afetados } \\
\text { atendidos ao dia } \\
\text { por unidade do } \\
\text { produto } \\
\end{array}$ & $\begin{array}{c}\text { Custo de } \\
\text { Estoque } \\
\text { (R\$/unidade) }\end{array}$ & $\begin{array}{c}\text { Penalidade } \\
\text { Falta } \\
\text { (R\$/unidade) }\end{array}$ & $\begin{array}{c}\text { Volume } \\
\text { (L) }\end{array}$ & $\begin{array}{c}\text { Massa } \\
(\mathrm{Kg})\end{array}$ \\
\hline Água 15L & 1 & 1,88 & 75,00 & 15 & 15 \\
\hline Kit Alimentação & 5 & 21,53 & 861,00 & 30 & 23 \\
\hline Kit Médico & 90 & 21,30 & 852,00 & 11 & 14 \\
\hline Kit Higiene Pessoal & 1 & 6,76 & 270,30 & 10 & 3 \\
\hline Kit Higiene Doméstica & 5 & 15,07 & 602,70 & 16 & 7 \\
\hline
\end{tabular}

Tabela A2: Características dos tipos de veículos.

\begin{tabular}{|c|c|c|c|}
\hline Veículos & Capacidade (L) & Capacidade (Kg) & $\begin{array}{l}\text { Custo de Operação } \\
(\mathbf{R} \$ / \mathbf{K m})\end{array}$ \\
\hline Caminhão & 30000 & 6000 & 1,25 \\
\hline Barco & 3000 & 600 & 2,17 \\
\hline Helicóptero & 115000 & 2250 & 1,32 \\
\hline
\end{tabular}

Tabela A3: Áreas afetadas.

\begin{tabular}{|c|l|r|}
\hline Áreas & \multicolumn{1}{|c|}{ Endereço } & \multicolumn{1}{c|}{ Afetados } \\
\hline ARE & Areal, RJ & 7000 \\
\hline BJD & Bom Jardim, RJ & 12380 \\
\hline NFR & Nova Friburgo, RJ & 180000 \\
\hline PTP & Petrópolis, RJ & 19000 \\
\hline SJV & São Jose do Vale do Rio Preto, RJ & 20682 \\
\hline SMD & Sumidouro, RJ & 15000 \\
\hline TRS & Teresópolis, RJ & 50500 \\
\hline
\end{tabular}

Tabela A4: Depósitos disponíveis.

\begin{tabular}{|l|l|}
\hline \multicolumn{1}{|c|}{ Depósitos } & \multicolumn{1}{c|}{ Endereço } \\
\hline 1- Igreja Santo Antônio / Cruz Vermelha & Rua Oliveira Botelho, 620, Teresópolis, RJ \\
\hline 2- Galpão do Meudon & Rua Tenente Luiz Meirelles, 3377, Teresópolis, RJ \\
\hline 3- Loja Maçônica Três Luz & Rua Padre Tintorio, 45, Teresópolis, RJ \\
\hline 4- Ginásio Poliesportivo Pedro Jahara & Rua Tenente Luiz Meirelles, 211, Teresópolis, RJ \\
\hline 5- 15 Grupamento de Bombeiros Militar & Avenida Barão do Rio Branco, 1957, Petrópolis, RJ \\
\hline 6- Sede da Cruz Vermelha de Nova Friburgo & Praça Getúlio Vargas, 92, Nova Friburgo, RJ \\
\hline
\end{tabular}


Tabela A5: Centros de auxílio disponíveis para uso.

\begin{tabular}{|c|c|c|c|}
\hline Centros de Auxílio & Endereço & $\begin{array}{c}\text { Custo } \\
\text { Operacional } \\
(\mathbf{R} \$ / \text { dia })\end{array}$ & $\begin{array}{l}\text { Capacidade } \\
\text { Centros (L) }\end{array}$ \\
\hline 1 - Igreja Wesleyana & $\begin{array}{l}\text { Estrada Philuvio Cerqueira, } 2700 \text {, } \\
\text { Petrópolis, RJ }\end{array}$ & 300 & 787441 \\
\hline $\begin{array}{l}2 \text { - Secretaria do Trabalho, } \\
\text { Assistência Social e Cidadania }\end{array}$ & $\begin{array}{l}\text { Rua Aureliano Coutinho, } 81 \text {, } \\
\text { Petrópolis, RJ }\end{array}$ & 300 & 1357235 \\
\hline $\begin{array}{l}3 \text { - CIEP (Centro Integrado de } \\
\text { Educação Pública) de Itaipava }\end{array}$ & $\begin{array}{l}\text { Estrada União e Industria, } 11.860 \text {, } \\
\text { Petrópolis, RJ }\end{array}$ & 600 & 9589769 \\
\hline $\begin{array}{l}4 \text { - } 26 \text { Batalhão da Polícia } \\
\text { Militar de Petrópolis }\end{array}$ & $\begin{array}{l}\text { Rua Domingos Silvério, s/n, } \\
\text { Petrópolis, RJ }\end{array}$ & 1000 & 26674126 \\
\hline 5 - SESC Quitandinha & $\begin{array}{l}\text { Avenida Joaquim Rolla, 2, } \\
\text { Petrópolis, RJ }\end{array}$ & 1000 & 11072139 \\
\hline 6 - SESI Petrópolis & $\begin{array}{l}\text { Avenida Barão do Rio Branco, } \\
\text { 2564, Petrópolis, RJ }\end{array}$ & 600 & 7946294 \\
\hline 7 - SENAI Petrópolis & Rua Bingen, 130, Petrópolis, RJ & 600 & 9190465 \\
\hline 8 - Fundação Leão XIII & $\begin{array}{l}\text { Rua General Osorio, 12, Petrópolis, } \\
\text { RJ }\end{array}$ & 600 & 9576291 \\
\hline $\begin{array}{l}9 \text { - Centro Integrado de } \\
\text { Educação Pública (CIEP) }\end{array}$ & $\begin{array}{l}\text { Estrada União e Industria, 2822, } \\
\text { Petrópolis, RJ }\end{array}$ & 600 & 7067686 \\
\hline $\begin{array}{l}10 \text { - Sede da Cruz Vermelha de } \\
\text { Petrópolis }\end{array}$ & Rua Carlos Gomes, 6, Petrópolis, RJ & 1000 & 20236980 \\
\hline $\begin{array}{l}11 \text { - Sede Cruz Vermelha } \\
\text { Teresópolis }\end{array}$ & $\begin{array}{l}\text { Rua Carmela Dutra, 661, } \\
\text { Teresópolis, RJ }\end{array}$ & 1000 & 24793049 \\
\hline $\begin{array}{l}12 \text { - Sede da Secretaria da } \\
\text { Saúde }\end{array}$ & $\begin{array}{l}\text { Avenida Feliciano Sodré, 675, } \\
\text { Teresópolis, RJ }\end{array}$ & 600 & 9766086 \\
\hline $\begin{array}{l}13-\text { Secretaria do } \\
\text { Desenvolvimento Social }\end{array}$ & $\begin{array}{l}\text { Avenida Alberto Torres, } 111 \text {, } \\
\text { Teresópolis, RJ }\end{array}$ & 300 & 1221844 \\
\hline $\begin{array}{l}14-16 \text { Grupamento de } \\
\text { Bombeiro Militar }\end{array}$ & Rua Guandu, 280, Teresópolis, RJ & 1000 & 19217848 \\
\hline 15 - SESC Teresópolis & $\begin{array}{l}\text { Avenida Delfim Moreira, 749, } \\
\text { Teresópolis, RJ }\end{array}$ & 1000 & 15003027 \\
\hline $\begin{array}{l}16 \text { - Igreja Missionária do } \\
\text { Amor em Cristo }\end{array}$ & $\begin{array}{l}\text { Avenida Delfim Moreira, 2020, } \\
\text { Teresópolis, RJ }\end{array}$ & 300 & 763603 \\
\hline $\begin{array}{l}17 \text { - Igreja Batista Dedo de } \\
\text { Deus }\end{array}$ & Rua Acre, 241, Teresópolis, RJ & 300 & 926351 \\
\hline 18 - Igreja Metodista & Rua Manoel Dias, Teresópolis, RJ & 300 & 640500 \\
\hline 19 - Pousada Saint German & Rua Sergipe, 650, Teresópolis, RJ & 600 & 7035451 \\
\hline $\begin{array}{l}20 \text { - Associação Promoção } \\
\text { Social Lopes Vincunha }\end{array}$ & $\begin{array}{l}\text { Rua Sebastiao Lacerda, 1393, } \\
\text { Teresópolis, RJ }\end{array}$ & 1000 & 14219930 \\
\hline
\end{tabular}


Tabela A6: Centros de auxílio disponíveis para uso (continuação).

\begin{tabular}{|c|c|c|c|}
\hline Centros de Auxílio & Endereço & $\begin{array}{c}\text { Custo } \\
\text { Operacional } \\
\text { (R\$/dia) }\end{array}$ & $\begin{array}{l}\text { Capacidade } \\
\text { Centros (L) }\end{array}$ \\
\hline $\begin{array}{l}21 \text { - Igreja Batista em Barra do } \\
\text { Imbuí }\end{array}$ & $\begin{array}{l}\text { Rua Doutor Oliveira, 314, } \\
\text { Teresópolis, RJ }\end{array}$ & 300 & 601837 \\
\hline 22 - Igreja de Cristo & $\begin{array}{l}\text { Rua Manoel Dias, 84, Teresópolis, } \\
\text { RJ }\end{array}$ & 300 & 587034 \\
\hline 23 - Igreja Serra dos Órgãos & $\begin{array}{l}\text { Rua Luiz Noguet Jr, 480, } \\
\text { Teresópolis, RJ }\end{array}$ & 300 & 1130393 \\
\hline 24 - Igreja de Deus no Brasil & $\begin{array}{l}\text { Av. Presidente Roosevelt, 56, } \\
\text { Teresópolis, RJ }\end{array}$ & 300 & 1033680 \\
\hline 25 - Igreja Cristã Evangélica & $\begin{array}{l}\text { Av. Almirante Lucio Meira, 171, } \\
\text { Teresópolis, RJ }\end{array}$ & 300 & 544800 \\
\hline 26 - Igreja Mornons & $\begin{array}{l}\text { Rua Manoel Jose Lebrão, } \\
\text { Teresópolis, RJ }\end{array}$ & 300 & 1222697 \\
\hline 27 - Igreja Metodista Central & $\begin{array}{l}\text { Rua Nilza Chiapeta fadigas, } 274 \text {, } \\
\text { Teresópolis, RJ }\end{array}$ & 300 & 1247341 \\
\hline 28 - Associação Nova Vida & $\begin{array}{l}\text { Estrada Teresópolis Friburgo, 5, } \\
\text { Campanha, Teresópolis, RJ }\end{array}$ & 300 & 994547 \\
\hline $\begin{array}{l}29 \text { - Assistência social de Nova } \\
\text { Friburgo }\end{array}$ & $\begin{array}{l}\text { Rua Augusto Spinelli, 160, Nova } \\
\text { Friburgo, RJ }\end{array}$ & 1000 & 13907801 \\
\hline $\begin{array}{l}30 \text { - Hospital Municipal Raul } \\
\text { Sertã }\end{array}$ & $\begin{array}{l}\text { Rua General Osorio, 324, Nova } \\
\text { Friburgo, RJ }\end{array}$ & 1000 & 14014608 \\
\hline $\begin{array}{l}31 \text { - Polo da Fundação da } \\
\text { Infância e Adolescência (FIA) }\end{array}$ & $\begin{array}{l}\text { Avenida Júlio Antônio Thuller, } 480 \\
\text { (28620-000), Nova Friburgo, RJ }\end{array}$ & 300 & 1021026 \\
\hline $\begin{array}{l}32-6 \text { Grupamento de } \\
\text { Bombeiros Militar }\end{array}$ & $\begin{array}{l}\text { Praça da Bandeira, 1027, Nova } \\
\text { Friburgo, RJ }\end{array}$ & 1000 & 21603101 \\
\hline $\begin{array}{l}33 \text { - Prefeitura de Nova } \\
\text { Friburgo }\end{array}$ & $\begin{array}{l}\text { Avenida Alberto Braune, 225, Nova } \\
\text { Friburgo, RJ }\end{array}$ & 300 & 563427 \\
\hline 34 - Batalhão da Polícia Militar & $\begin{array}{l}\text { Rua Venâncio Pereira Veloso, } 78 \text {, } \\
\text { Bom Jardim, RJ }\end{array}$ & 1000 & 17992467 \\
\hline $\begin{array}{l}35 \text { - Delegacia Policial de } \\
\text { Sumidouro }\end{array}$ & $\begin{array}{l}\text { Rua Faria Oliveira, n 51, } \\
\text { Sumidouro, RJ }\end{array}$ & 1000 & 11020328 \\
\hline $\begin{array}{l}36 \text { - Defesa Civil de Santa } \\
\text { Maria Madalena }\end{array}$ & $\begin{array}{l}\text { Rua Vereador Dilson Batista Soares, } \\
\text { 45, Santa Maria Madalena, RJ }\end{array}$ & 1000 & 20302282 \\
\hline $\begin{array}{l}37 \text { - Delegacia Policial de } \\
\text { Trajano de Moraes }\end{array}$ & $\begin{array}{l}\text { Rua Ruy Barbosa, s/n, Trajano de } \\
\text { Moraes, RJ }\end{array}$ & 600 & 9242322 \\
\hline $\begin{array}{l}38 \text { - Delegacia Policial de } \\
\text { Sapucaia }\end{array}$ & $\begin{array}{l}\text { Rua } 15 \text { de Novembro, 40, Sapucaia, } \\
\text { RJ }\end{array}$ & 600 & 6964587 \\
\hline $\begin{array}{l}\text { 39-Delegacia Policial de São } \\
\text { Sebastião do Alto }\end{array}$ & $\begin{array}{l}\text { Rua Cel. Francisco Salustiano Pinto, } \\
\text { 210, São Sebastiao do Alto, RJ }\end{array}$ & 1000 & 15198990 \\
\hline $\begin{array}{l}\text { 40-Prefeitura de São Sebastião } \\
\text { do Alto }\end{array}$ & $\begin{array}{l}\text { Rua Dr. Júlio Vieitas, 88, São } \\
\text { Sebastiao do Alto, RJ }\end{array}$ & 300 & 991795 \\
\hline
\end{tabular}

